\title{
Desempenho do processo de concentração de extratos de própolis por nanofiltração
}

\author{
Performance of nanofiltration concentration process in propolis extracts
}

\author{
Beatriz Camargo Barros de Silveira MELLOํㅗ , José Carlos Cunha PETRUS², Miriam Dupas HUBINGER ${ }^{1 *}$
}

\section{Resumo}

A própolis é um produto natural de interesse devido às suas importantes características funcionais. A nanofiltração foi testada para a concentração do extrato proveniente da própolis verde, partindo-se de extratos alcoólico e aquoso. Foi utilizada uma membrana em módulo espiral, de massa molar de corte média entre 150 e 300 g.mol ${ }^{-1}$. Avaliou-se a influência da variação de pressão, temperatura e velocidade tangencial no fluxo de permeado, e a ocorrência de histerese na membrana. Obteve-se fluxo médio de permeado de $12,0 \mathrm{~L} / \mathrm{h} . \mathrm{m}^{2}$ para a solução alcoólica e de 25,0 L/h.m² para a aquosa. A pressão foi acrescida gradativamente de 2,0 a 5,0 bar, proporcionando variação diretamente proporcional no fluxo de permeado e também no fouling, chegando a $32 \%$ em 5,0 bar. O fluxo de permeado foi diretamente proporcional ao aumento da temperatura e da velocidade tangencial. A histerese foi medida a 30 e $40^{\circ} \mathrm{C}$, demonstrando a característica elástica e reversível da membrana. A eficiência do processo foi medida através das taxas de retenção de flavonoides e compostos fenólicos, obtendo-se retenção de flavonoides de aproximadamente $99 \%$ para a solução aquosa e $90 \%$ para a solução alcoólica e de compostos fenólicos de cerca de 80 e $24 \%$ para soluções aquosa e alcoólica, respectivamente.

Palavras-chave: própolis; nanofiltração; flavonoides; membranas.

\begin{abstract}
Propolis is a natural product with great appeal to consumers and researchers due to its important functional properties. Nanofiltration was tested to concentrate the extract derived from propolis produced by Brazilian bees using a water- and an alcohol-based extract. A spiral membrane module with average molar mass cut-off around 150 to $300 \mathrm{~g} \cdot \mathrm{mol}^{-1}$ was used. The influence of pressure, temperature and tangential velocity on the permeate flux was evaluated and hysteresis in the membrane was analyzed. An average permeate flux around $12.0 \mathrm{~L} / \mathrm{h} . \mathrm{m}^{2} \mathrm{was}$ obtained for the alcoholic solution and $25.0 \mathrm{~L} / \mathrm{h} . \mathrm{m}^{2}$ for the aqueous solution. The pressure was varied from 2 to 5.0 bar, providing variation directly proportional to the increase of permeate flux, and also to the increase of fouling, which reached $32 \%$ at 5.0 bar. The permeate flux also was directly proportional to the increase in temperature and tangential flow. Hysteresis was measured at 30 and $40{ }^{\circ} \mathrm{C}$ and demonstrated the elastic and reversible characteristic of the membrane. The process efficiency was measured by retention index of flavonoids and phenolic compounds. Around $99 \%$ of flavonoids in aqueous solution and $90 \%$ in ethanol solution were retained, and in the phenolic compounds, around 80 and $24 \%$ for the aqueous and the ethanol solutions respectively were retained.
\end{abstract}

Keywords: propolis; nanofiltration; flavonoids; membranes.

\section{Introdução}

Observa-se, cada vez mais, a procura por hábitos de vida e alimentares mais saudáveis, bem como o consumo de alimentos com propriedades funcionais. Neste contexto, os produtos apícolas vêm despertando interesse, tanto nos consumidores quanto nos pesquisadores, graças à sua composição química. A própolis, em especial, destaca-se quanto às suas propriedades terapêuticas (antimicrobiana, anti-inflamatória, cicatrizante e anestésica) que podem ser utilizadas nas indústrias farmacêutica e de alimentos.

Os compostos fenólicos correspondem a aproximadamente $50 \%$ dos constituintes da própolis (KRELL, 1996), mas pode ocorrer uma variação deste percentual de acordo com a região de coleta do produto. Os seus efeitos terapêuticos têm sido atribuídos aos diversos compostos fenólicos presentes, principalmente os flavonoides (PARK et al., 1998).
A própolis bruta contém substâncias solúveis em óleo ou em água e também solúveis nestes dois solventes. Entretanto, a maioria dos componentes da própolis é solúvel em óleo, por isso, o método de extração de própolis mais utilizado, emprega o álcool etílico hidratado como solvente. Este solvente é utilizado porque a própolis apresenta baixa solubilidade em água, em razão das características apolares da maior parte das substâncias que a compõem. No entanto, o extrato alcoólico possui vários inconvenientes como o sabor residual, além de causar reações adversas e contra indicações, decorrentes do uso do álcool como solvente que pode provocar também a restrição do comércio deste extrato em alguns países (KONISHI et al., 2004).

Ainda é grande o interesse dos pesquisadores em produzir um extrato de própolis com as mesmas qualidades do extrato alcoólico, mas sem as desvantagens que este último apresenta.

Recebido para publicação em 17/3/2008

Aceito para publicação em 7/1/2009 (003324)

Departamento de Engenharia de Alimentos, Faculdade de Engenharia de Alimentos, Universidade Estadual de Campinas, CP 6121, Campinas - SP, CEP 13083-970, Brasil,

e-mail:mhub@fea.unicamp.br

2 Departamento de Engenharia Química e Engenharia de Alimentos, Universidade Federal de Santa Catarina, CP 476, Florianópolis - SC, CEP 88040-900, Brasil

${ }^{*}$ A quem a correspondência deve ser enviada 
Acredita-se que a concentração do extrato aquoso de própolis pode resultar num produto com melhores características funcionais, semelhantes às do extrato alcoólico em relação à quantidade de substâncias fenólicas por volume de extrato. Park et al., 1998, estudaram extratos de própolis preparados apenas com água como solvente e extratos preparados com uma mistura de água e álcool. Além disso, outros solventes têm sido testados como o propileno glicol e a glicerina (KRELL, 1996).

Independente do solvente usado em sua preparação, o extrato de própolis muitas vezes precisa ser concentrado antes de ser utilizado industrialmente. Nas pesquisas recentes, verifica-se uma preocupação quanto à possível interferência indesejável do solvente sobre as características dos compostos de interesse presentes no extrato da própolis (KRELL, 1996). Dessa forma, o estudo de processos de concentração, que não utilizam altas temperaturas, como aqueles que empregam membranas, podem ser alternativas frente aos processos utilizados tradicionalmente, como a evaporação, a liofilização e a destilação, que necessitam de alta demanda energética.

O processo de concentração por membranas vem crescendo nos últimos anos, graças às vantagens de se utilizar baixas temperaturas sem mudança do estado físico do solvente e, consequentemente, com menor consumo energético (MATTA; MORETTI; CABRAL, 2004). Este processo é baseado no princípio da permeação seletiva de moléculas de soluto em membranas semipermeáveis, poliméricas ou inorgânicas, utilizando como força motriz, para a transferência de massa através da membrana, a pressão mecânica (MAROULIS; SARAVACOS, 2003). A nanofiltração é uma operação unitária de separação por membrana que vem tendo importantes aplicações, tais como a recuperação de solventes resultantes da filtração de óleos, separação e reuso de catalisadores na indústria farmacêutica, troca de solventes na indústria química (GEENS et al., 2006) e concentração de vinhos (BANVOLGYI et al., 2006) e sucos (VINCZE et al., 2006).

Durante o processamento por membranas, alguns compostos presentes na solução de alimentação tendem a se acumular na superfície da membrana, formando uma camada que oferece resistência adicional ao fluxo de solvente, apenas eliminada durante os procedimentos de limpeza, acarretando em diminuição do fluxo de permeado durante o processamento. Esta camada, conhecida como camada gel, ocorre devido ao aumento na concentração dos solutos retidos próximo à superfície da membrana, formando um gradiente de concentração entre a superfície da membrana e a zona da corrente de alimentação. Além da camada gel, ocorre durante a filtração o fouling, que se traduz na penetração de solutos presentes na solução nos poros da membrana. A intensidade desse fenômeno durante o processo depende da interação entre as moléculas constituintes da membrana e as moléculas presentes em solução, das condições operacionais e tempo de operação (PETRUS, 1997; HABERT; BORGES; NOBREGA, 2006).

Portanto, a viabilidade do processo de concentração por membranas depende, em grande parte, das condições envolvidas no processo como as propriedades da membrana, afinidade membrana-soluto, temperatura da solução, pressão transmembrana. O controle destas variáveis pode amenizar os efeitos indesejáveis como a formação de camada de gel ou de polarização, fouling, histerese, que de certa forma mede a elasticidade da membrana, evitando uma redução drástica do fluxo de permeado. Portanto, devem-se avaliar corretamente os principais parâmetros operacionais, pois, aumentando-se a pressão, a velocidade de circulação e a temperatura, pode-se aumentar o rendimento do processo, mas também pode levar a um maior consumo de energia (PILIPOVIC; RIVEROL, 2005). Assim, se justifica o estudo e o estabelecimento de parâmetros operacionais adequados durante o processamento com membranas (USHIKUBO; WATANABE; VIOTTO, 2006).

Este trabalho teve como objetivo o uso da nanofiltração na concentração de extratos aquoso e etanólico de própolis. Estudaram-se também os efeitos da pressão, temperatura e velocidade tangencial sobre o fluxo de permeado e também a ocorrência de histerese na membrana durante o processamento. A avaliação final foi feita através da análise dos flavonoides e compostos fenólicos na solução de alimentação, no concentrado e no permeado para se verificar a retenção destes compostos pela membrana de nanofiltração.

\section{Material e métodos}

\subsection{Própolis}

A própolis bruta foi obtida no Estado de São Paulo, proveniente de colmeias de abelhas da espécie Apis mellifera. Todas as amostras foram retiradas de um mesmo lote, para que não houvesse diferença em relação aos constituintes do produto devido às variabilidades quanto ao clima e flora. Todo o lote foi mantido sob refrigeração a $4{ }^{\circ} \mathrm{C}$ e, posteriormente, usado na preparação dos extratos.

O extrato etanólico foi preparado a partir da própolis bruta triturada em liquidificador convencional à qual se adicionou álcool etílico $80 \%$. A mistura foi mantida em temperatura ambiente por sete dias, sob agitação periódica. Após esse período, a solução foi centrifugada (centrífuga Beckman - Allegra 25R, Beckman Coulter, Alemanha) a 8.800 g, mantendo-se a temperatura a $20^{\circ} \mathrm{C}$ por 20 minutos. O sobrenadante foi filtrado em papel de filtro e colocado sob refrigeração a $4{ }^{\circ} \mathrm{C}$. Após 3 horas, o líquido foi novamente filtrado para a remoção de ceras. Finalmente, o líquido foi armazenado sob temperatura ambiente, ao abrigo da luz.

O extrato aquoso foi obtido da mesma forma que o extrato etanólico, utilizando-se água deionizada. Ambos os extratos foram preparados na proporção de $20 \%$ de própolis para $80 \%$ de solvente. Os extratos foram avaliados de acordo com o seu teor de flavonoides e compostos fenólicos para efeito de comparação com os produtos concentrados. O diagrama de fluxo do processamento está apresentado na Figura 1.

\subsection{Determinação de flavonoides totais}

A metodologia utilizada está descrita no Boletim Informativo da Associação Japonesa de Saúde e Nutrição (1994) e por Park et al. (1995), ambos citados por Moura (2000). Em tubos de ensaio contendo $0,5 \mathrm{~mL}$ do extrato de própolis, 
previamente diluídos na proporção de 1:10, foram adicionados $0,1 \mathrm{~mL}$ de nitrato de alumínio $10 \%, 0,1 \mathrm{~mL}$ de acetato de potássio 1 mol.L $\mathrm{L}^{-1}$ e 4,3 mL de álcool etílico $80 \%$. As amostras foram homogeneizadas e, após 40 minutos de repouso, fez-se a leitura espectrofotométrica a $415 \mathrm{~nm}$. A curva padrão foi preparada utilizando-se solução de quercetina em concentrações de 5 a $110 \mu \mathrm{g} \cdot \mathrm{mL}^{-1}$.

\subsection{Determinação de substâncias fenólicas totais}

A determinação de polifenois no extrato de própolis foi feita pelo método colorimétrico de Folin-Ciocalteau (KUMAZAWA et al., 2004). Em tubos de ensaio, foram homogeneizados $0,5 \mathrm{~mL}$ da solução de própolis diluída em 1:10 com 0,5 mL do reagente de Folin-Ciocalteau e 0,5 mL de $\mathrm{Na}_{2} \mathrm{Co}_{3}$ a $10 \%$. As amostras foram homogeneizadas e mantidas em temperatura ambiente, sob o abrigo da luz por 1 hora, para posterior leitura espectrofotométrica a $760 \mathrm{~nm}$. Para elaboração da curva padrão, utilizou-se solução de ácido gálico dissolvido em água destilada na concentração de 5 a $200 \mu \mathrm{g} \cdot \mathrm{mL}^{-1}$. Os compostos fenólicos totais foram expressos como equivalentes de ácido gálico $\left(\mathrm{mg} \cdot \mathrm{g}^{-1}\right)$.

\subsection{Concentração por membrana}

O processo de concentração foi conduzido em sistema de filtração tangencial em escala piloto. Neste sistema, pode-se trabalhar de forma "fechada", com todo o produto permeado retornando ao sistema, e de forma "aberta", em que o permeado é retirado, resultando na concentração da solução de alimentação. Neste experimento, utilizou-se o sistema fechado. A definição pelo processo de nanofiltração foi resultado de ensaios obtidos por Mello (2008), em módulo de bancada com agitação, simulando o escoamento tangencial, com os extratos aquosos e alcoólicos. Nesses ensaios, foram utilizadas membranas de ultrafiltração, nanofiltração e osmose reversa. A eficiência destas membranas foi avaliada através da capacidade de retenção dos compostos de interesse - flavonoides e compostos fenólicos, e pela análise do permeado de cada membrana utilizada. As membranas de nanofiltração e de osmose reversa foram as que apresentaram menores quantidades desses compostos no permeado, evidenciando uma maior capacidade de retenção. No entanto, o uso de nanofiltração requer menos energia que a osmose reversa devido à menor pressão necessária para a separação. Dessa forma, para o processo tangencial, utilizandose o equipamento piloto, foi utilizada uma membrana de nanofiltração na configuração espiral, fabricada pela Osmonics (Minnetonka, EUA), com área filtrante útil de 0,6 $\mathrm{m}^{2}$. Esta membrana, segundo informações do fabricante, apresenta rejeição de $98 \%$ ao $\mathrm{MgSO}_{4}$, à pressão de 6,9 bar e temperatura de $25{ }^{\circ} \mathrm{C}$. Durante a nanofiltração, variaram-se a pressão transmembrana, temperatura e velocidade tangencial do extrato, para que fossem avaliados os efeitos dessas variáveis sobre o fluxo de permeado.

A avaliação do fluxo de permeado, para ambos os extratos, foi feita à pressão de 6,0 bar e à temperatura de $20^{\circ} \mathrm{C}$. O tempo de operação foi de 60 minutos para a solução aquosa e de 30 minutos para a solução alcoólica. Nos testes efetuados para análise do efeito da pressão no processo, a temperatura foi

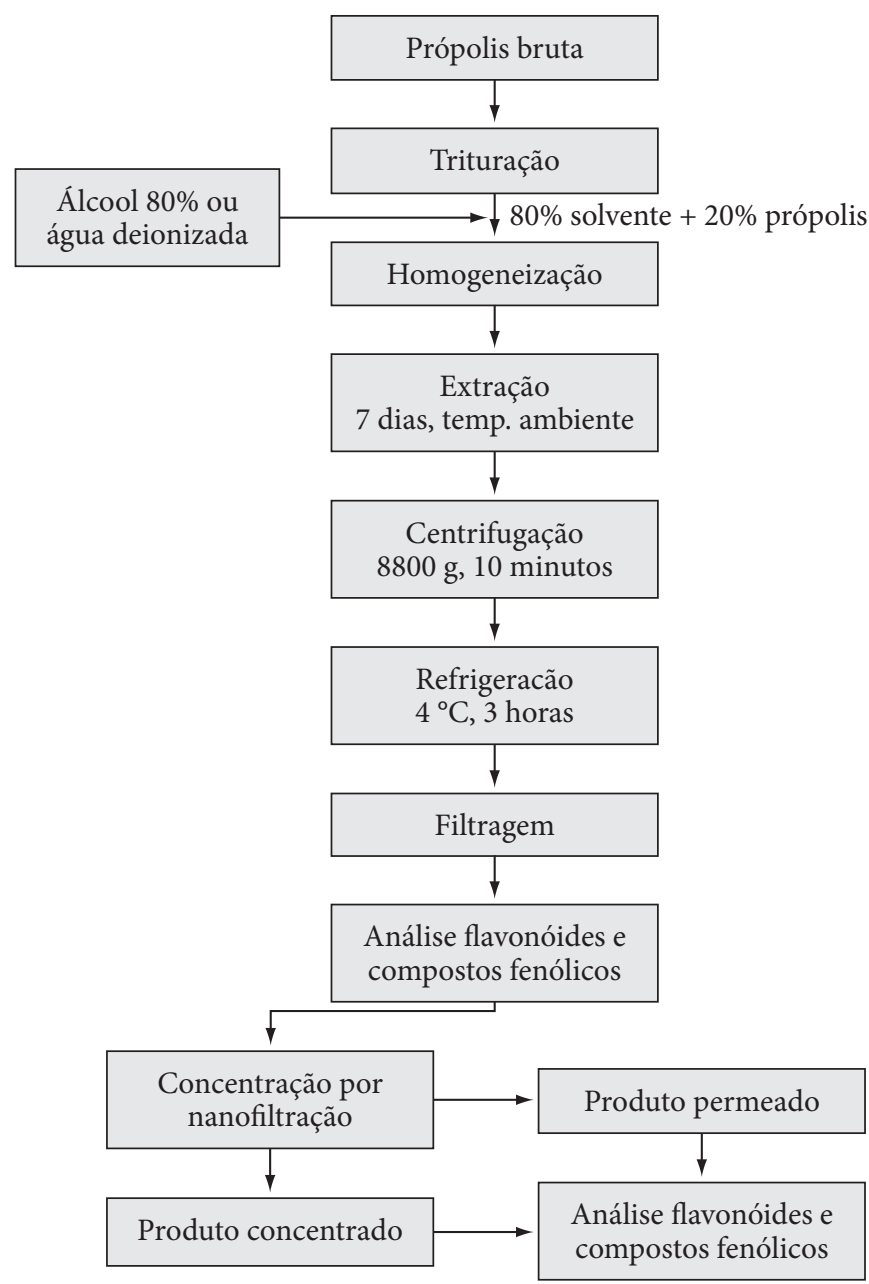

Figura 1. Diagrama de fluxo do processo de obtenção do extrato de própolis e concentração por nanofiltração.

mantida em $20 \pm 2{ }^{\circ} \mathrm{C}$, enquanto variou-se a pressão de 1,0 a 5,0 bar, com a finalidade de avaliar o efeito da pressão no fluxo de permeado e a ocorrência de fouling. A análise da taxa de fouling, que indica o entupimento dos poros da membrana por solutos presentes na solução de alimentação, foi feita comparando-se o fluxo de permeado obtido pela concentração do extrato aquoso de própolis com o fluxo obtido pelo processamento de água destilada pura.

$\mathrm{O}$ efeito da temperatura no processo foi analisado em duplicata através do aumento gradual de 20 a $45^{\circ} \mathrm{C}$ e pressão fixada em 6,0 bar. Baixas temperaturas foram usadas para se evitar a degradação de compostos de importância nutricional presentes na solução e reduzir o consumo energético. A temperatura de degradação dos flavonoides depende de sua estrutura química e da interação entre eles. Em emulsões de extratos de plantas, ocorreu a degradação de flavonoides a partir de $40{ }^{\circ} \mathrm{C}$ (BABY et al., 2007). A preparação de alimentos contendo flavonoides, incluindo lavagem, descascamento e cozimento a temperaturas próximas de $100{ }^{\circ} \mathrm{C}$, acarreta uma perda média destes compostos de até 53\% (PETERSON; 
DWYER, 1998). Além disso, Cvek et al. (2007) estudaram o processo de extração da própolis em temperatura ambiente, $50,70{ }^{\circ} \mathrm{C}$ e ebulição. Analisando os compostos fenólicos e flavonoides, concluíram que a temperatura ambiente é a que melhor preserva os compostos de interesse.

A velocidade tangencial foi estudada no intervalo de 0,2 a $1,0 \mathrm{~m} \cdot \mathrm{s}^{-1}$, a $20^{\circ} \mathrm{C}$ e pressão de $6,0 \mathrm{bar}$, analisando-se a sua influência na variação do fluxo de permeado.

O fluxo de permeado ( $J$ ), para todas as análises, foi calculado de acordo com a Equação 1:

$$
J=\frac{V_{p}}{t \cdot A_{m}}
$$

em que:

$\mathrm{V}_{\mathrm{p}}=$ volume do permeado;

$\mathrm{t}=$ tempo; $\mathrm{e}$

$\mathrm{A}_{\mathrm{m}}=$ área da membrana.

$\mathrm{O}$ fator de concentração (F) indica a relação entre a quantidade de solução concentrada obtida em relação à solução inicial de alimentação, e foi determinado utilizando-se a Equação 2:

$F=\frac{V_{a}}{V_{r}}$

em que:

$\mathrm{V}_{\mathrm{a}}=$ volume da solução de alimentação; e

$\mathrm{V}_{\mathrm{r}}=$ volume do retentado.

\section{Resultados e discussão}

O fluxo médio de permeado durante a nanofiltração dos extratos de própolis foi de $24,43 \mathrm{~L} / \mathrm{h} \cdot \mathrm{m}^{2}$ para a solução aquosa e $12,11 \mathrm{~L} / \mathrm{h} . \mathrm{m}^{2}$ para a solução alcoólica. Esta diferença nos valores de fluxo entre os extratos pode ser decorrência da maior ou menor interação dos solventes - água e álcool com a membrana. Acredita-se, também, que diferentes compostos extraídos da própolis pelo álcool podem promover alteração

Tabela 1. Teor de flavonoides e fenólicos após concentração dos extratos alcoólico e aquoso.

\begin{tabular}{llcc}
\hline & \multicolumn{1}{c}{ Solução } & $\begin{array}{c}\text { Teor flavonoides } \\
\left(\mathrm{mg} \cdot \mathrm{g}^{-1}\right)^{\mathrm{a}}\end{array}$ & $\begin{array}{c}\text { Teor fenólicos } \\
\left(\mathrm{mg} \cdot \mathrm{g}^{-1}\right)^{\mathrm{b}}\end{array}$ \\
\hline Extrato & Inicial & $69,35 \pm 0,38$ & $98,74 \pm 0,96$ \\
Alcoólico & Concentrado & $71,93 \pm 0,21$ & $105,08 \pm 1,5$ \\
& Permeado & $6,95 \pm 2,49$ & $75,07 \pm 2,1$ \\
Extrato & Inicial & $23,67 \pm 2,14$ & $36,57 \pm 0,35$ \\
Aquoso & Concentrado & $96,76 \pm 2,35$ & $104,74 \pm 1,41$ \\
& Permeado & $0,003 \pm 0,003$ & $7,51 \pm 1,61$
\end{tabular}

Valores representam média \pm desvio padrão $(\mathrm{n}=3)$.

aequivalentes de quercetina.

bequivalentes de ácido gálico. na viscosidade da solução inicial. Estes compostos apresentam característica de adesividade, podendo se fixar à membrana e ocasionar maior fouling e aumento da camada de gel formada na membrana, resultando na redução do fluxo de permeado. A Figura 2 apresenta os resultados de fluxo de permeado obtidos nestes experimentos.

Durante o processamento em sistema aberto, foi possível concentrar a solução aquosa para $25 \%$ do seu volume inicial e a solução alcoólica para $33 \%$. Não foi possível obter maior concentração, devido às limitações do equipamento. A tabela 1 apresenta as características do extrato de própolis nas diferentes etapas do processo (solução inicial e permeado), em relação aos teores de flavonoides e compostos fenólicos.

Tsui et al. (2007) estudaram a purificação do extrato de milho em solução alcoólica para produção de xantofila, utilizando-se a nanofiltração. Esses autores obtiveram fluxo de permeado da ordem de $10,0 \mathrm{~L} / \mathrm{h} \cdot \mathrm{m}^{2}$, à pressão de 27 bar e $50^{\circ} \mathrm{C}$. Hossain (2003) estudou o processo de concentração de antocianina por ultrafiltração obtida a partir de resíduos resultantes do processamento de cassis. Foram utilizadas diferentes membranas, e os autores obtiveram valores de fluxo permeado máximo de $17,3 \mathrm{~L} / \mathrm{h} \cdot \mathrm{m}^{2}$ a 1,4 bar e $18^{\circ} \mathrm{C}$. Banvolgyi et al. (2006) estudaram o processo de concentração de vinho tinto (rico em polifenois, álcool e açúcares) por nanofiltração, em diferentes temperaturas de processamento e pressão de 20 bar e obtiveram valores de fluxo de permeado de $10,0,15,0$ e $20,0 \mathrm{~L} / \mathrm{h} \cdot \mathrm{m}^{2}$ para 30,40 e $50{ }^{\circ} \mathrm{C}$, respectivamente. $\mathrm{O}$ processo de concentração do vinho tinto pode ser considerado como o mais próximo da solução alcoólica de própolis, já que possuem compostos comuns em solução e utilizam o álcool como solvente.

Para os extratos de própolis foram utilizadas pressões relativamente baixas (6,0 bar), quando comparadas a outros processos estudados na literatura. Entretanto, foram obtidos fluxos de permeado semelhantes, evidenciando a viabilidade da nanofiltração a baixas pressões, resultando em menor consumo energético.

A avaliação do efeito da pressão, temperatura e velocidade tangencial no fluxo de permeado foi realizada utilizando-se

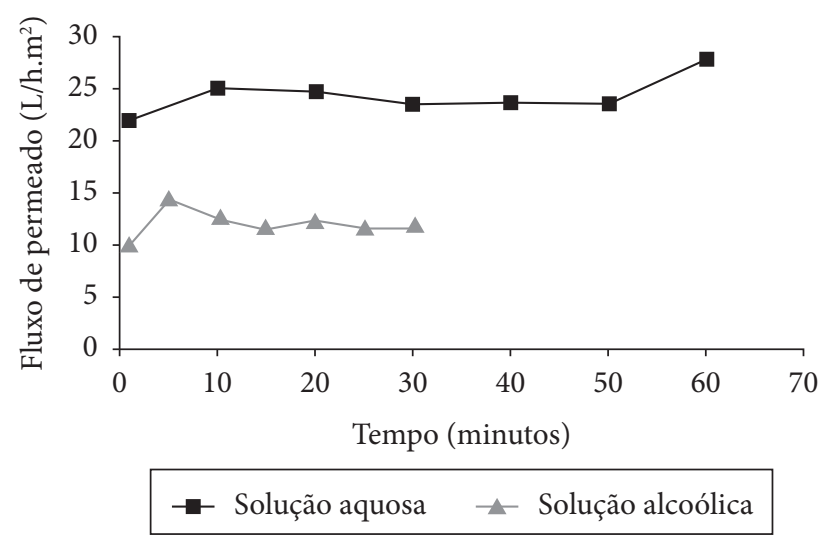

Figura 2. Fluxo de permeado dos extratos aquoso e alcoólico de própolis em função do tempo de processamento, a $20^{\circ} \mathrm{C}$ e 6,0 bar. 
apenas a solução aquosa devido à sua maior facilidade de manuseio e de limpeza da membrana, além de menores riscos de inflamabilidade.

Desconsiderando-se os efeitos de compactação da membrana, formação da camada gel e fouling, a variação de pressão seria diretamente proporcional ao fluxo de permeado dentro de certos limites. Entretanto, o uso de pressões mais elevadas pode levar a uma maior compactação da membrana, resultando na formação de uma camada gel mais intensa. $\mathrm{O}$ fouling resultante da filtração do extrato fica evidente quando se compara o seu fluxo permeado àquele da água destilada, sob as mesmas condições operacionais, como mostrado na Figura 3.

Miranda (2005), ao estudar a concentração do suco de melancia utilizando tecnologia de membranas, observou que o efeito de fouling é amenizado com a redução da pressão utilizada, mas não foi influenciado pela temperatura. Assim, mesmo para soluções com diferentes composições, o efeito do fouling geralmente é menos acentuado quando se trabalha a menores pressões. Entretanto, a redução do fluxo de permeado, provocada pela diminuição da pressão pode tornar o processo economicamente inviável devido à baixa produtividade do sistema.

É sabido que o aumento de temperatura reduz a viscosidade de uma solução e aumenta a sua difusividade através da camada gel e da própria membrana. $\mathrm{O}$ efeito da temperatura no processamento do extrato de própolis aquoso é mostrado na Figura 4.

O aumento de temperatura leva ao aumento no fluxo de permeado, graças à redução da viscosidade da solução. Entretanto, temperaturas muito altas podem elevar o grau de compactação da membrana ou mesmo alterar suas propriedades, podendo ocorrer aumento aparente do tamanho dos poros e alteração da interação entre membrana e solução, interferindo no processo de concentração (PETRUS, 1997).

Pela Figura 4, observa-se que houve um acréscimo no fluxo permeado, diretamente proporcional ao aumento de temperatura. $\mathrm{O}$ aumento de $25{ }^{\circ} \mathrm{C}$ na solução inicial, resultou num aumento de aproximadamente $100 \%$ no fluxo permeado.

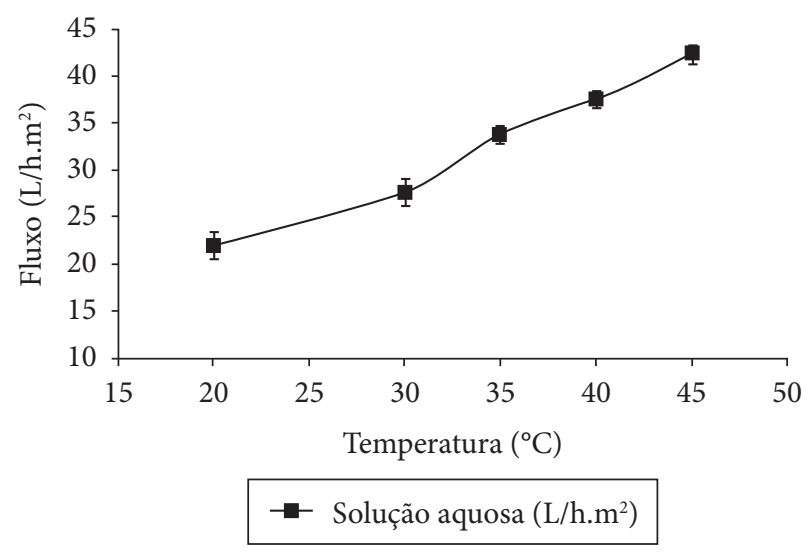

Figura 3. Efeito da pressão sobre os fluxos de permeado do extrato aquoso de própolis e de água destilada em função da pressão a $20{ }^{\circ} \mathrm{C}$.
No entanto, o uso de temperaturas elevadas deve ser investigado, para se evitar ou amenizar possíveis alterações térmicas na estrutura dos compostos de interesse. Estas alterações podem, inclusive, resultar em perda das atividades biológica e nutricional destes compostos.

Trabalho visando à concentração de outro produto, através da nanofiltração, como o vinho tinto (BANVOLGYI et al., 2006), mostrou que um aumento de $20^{\circ} \mathrm{C}$ na temperatura de processo, também resultou em aumento no fluxo de permeado da ordem de $100 \%$.

As membranas orgânicas possuem, pela sua própria natureza, uma tendência à compactação quando submetidas a altas pressões. Esta compactação pode ser parcialmente ou totalmente reversível e este fenômeno é conhecido como histerese. Esse efeito da pressão sobre a membrana foi avaliado neste trabalho, utilizando-se a solução aquosa de própolis, às temperaturas de 30 e $40^{\circ} \mathrm{C}$. A pressão foi acrescida de 1 a 7 bar e, na sequência, reduzida até 2,5 bar. Os resultados são mostrados nas figuras 5 e 6.

Observa-se que houve pequena variação no fluxo de permeado quando se elevou e quando se decresceu a pressão, para ambas as temperaturas, mostrando a reversibilidade na compactação da membrana.

Em trabalho realizado por Petrus (1997), ficou evidenciado que durante a ultrafiltração de suco de maçã, utilizando-se membrana polimérica, o fenômeno da histerese foi pronunciado, ocorrendo variação importante de fluxo de permeado durante a compactação e descompactação da membrana, diferentemente do ocorrido no presente trabalho. Por outro lado, naquele mesmo trabalho, verificou-se que um aumento da temperatura não resultou em diferença significativa no comportamento da membrana.

A turbulência junto à superfície filtrante, seja em filtração perpendicular ou tangencial, controla de maneira importante a formação da zona de polarização e a espessura da camada de gel. Esse efeito de turbulência é mais pronunciado na filtração tangencial, na qual a solução escoa à alta velocidade junto à membrana. Desta forma, a velocidade de circulação da solução,

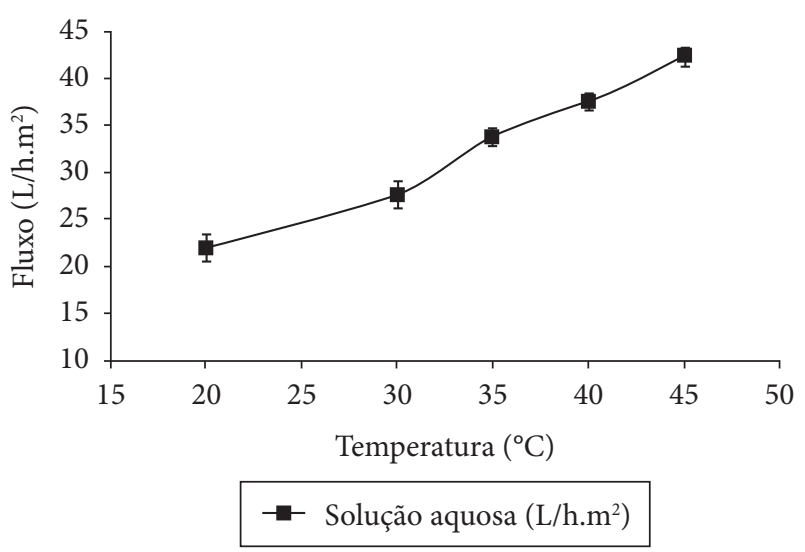

Figura 4. Fluxo de permeado em função da temperatura à pressão de 6,0 bar. 
durante a concentração, tem fundamental importância sobre o fluxo de permeado. $\mathrm{O}$ aumento da velocidade tangencial gera um aumento na turbulência da solução junto à membrana, diminuindo os efeitos adversos da zona de polarização. Neste trabalho, verificou-se que o fluxo permeado foi proporcional ao aumento da velocidade tangencial, conforme mostrado na Figura 7.

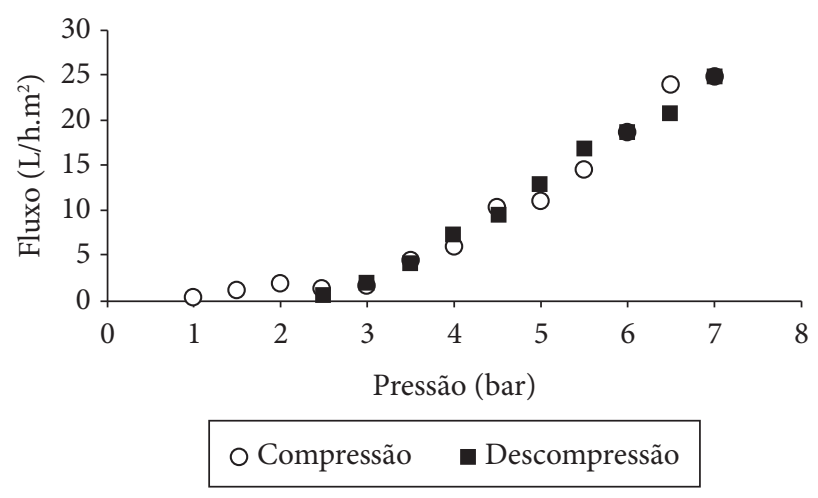

Figura 5. Fenômeno da histerese na membrana, utilizando-se solução aquosa de própolis a $30^{\circ} \mathrm{C}$.

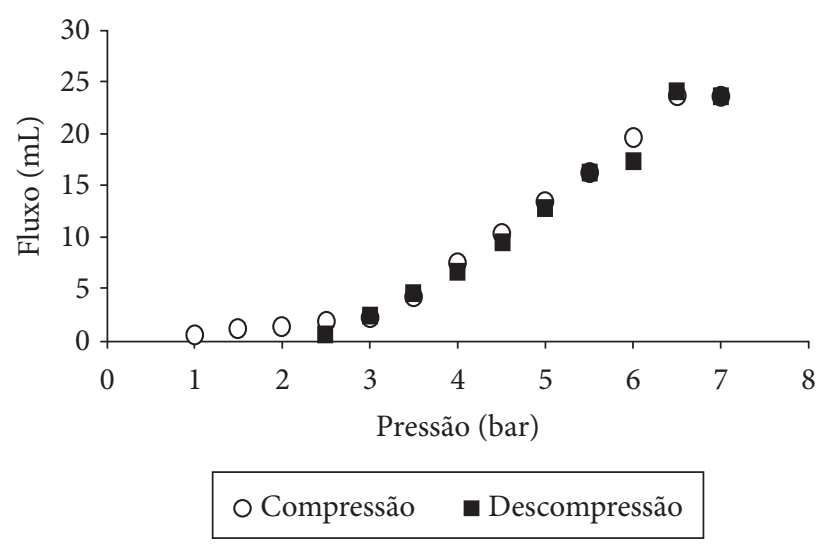

Figura 6. Fenômeno da histerese na membrana, utilizando-se solução aquosa de própolis a $40^{\circ} \mathrm{C}$.

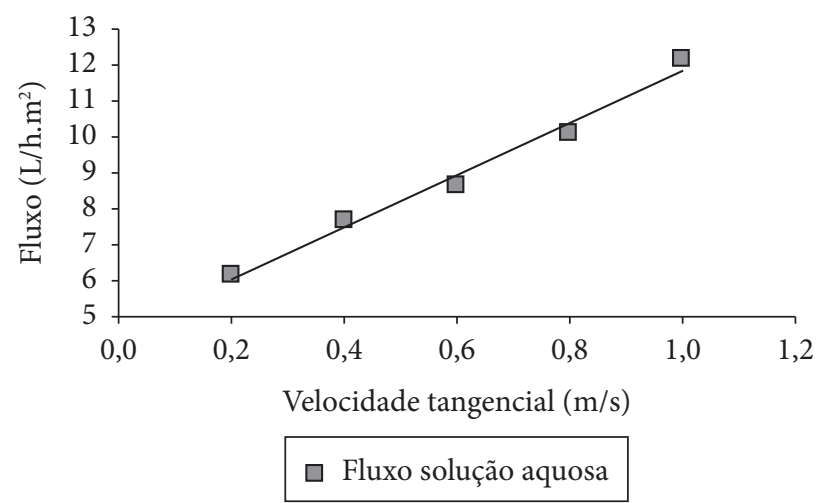

Figura 7. Efeito da velocidade tangencial sobre o fluxo de permeado a $20^{\circ} \mathrm{C}$ e 6,0 bar.

\section{Conclusões}

Os resultados obtidos mostraram que é possível a obtenção de uma solução de própolis concentrada, em função dos baixos teores dos compostos de interesse presentes no permeado, em especial para o extrato aquoso de própolis. A partir de fatores de concentrações mais elevados do que aqueles utilizados neste trabalho, certamente poderão ser obtidos extratos com alta concentração de flavonoides e compostos fenólicos a partir de extratos diluídos.

$\mathrm{O}$ uso de condições operacionais adequadas, tais como velocidade tangencial, temperatura e pressão levam a maiores valores de fluxo de permeado, fator importante para a aplicação industrial do processo. Finalmente, verificou-se que a membrana de nanofiltração comportou-se de forma elástica durante os ensaios de histerese, evidenciando a reversibilidade da compactação.

\section{Agradecimentos}

Ao Conselho Nacional de Desenvolvimento Científico e Tecnológico $(\mathrm{CNPq})$, à Fundação de Amparo à Pesquisa do Estado de São Paulo (FAPESP) e à CAPES, através do Programa Nacional de Cooperação Acadêmica (PROCAD), pelo apoio financeiro ao projeto.

\section{Referências bibliográficas}

BABY, A. R. et al. Accelerated chemical stability data of O/W fluid emulsions containing the extract of Trichilia catigua Adr. Juss (and) Ptychopetalum olacoides Bentham. Revista Brasileira de Ciências Farmacêuticas, v. 43, n. 3, p. 405-412, 2007.

BANVOLGYI, S. et al. Concentration of red wine by nanofiltration. Desalination, v. 198, p. 8-15, 2006.

CVEK, J. et al. Optimisation of an extraction procedure and chemical characterisation of croatian propolis tintures. Phytochemical Analysis, v. 18, n. 5, p. 451-459, 2007.

GEENS, J. et al. Modelling of solute transport in non-aqueous nanofiltration. Journal of Membrane Science, v. 281, n. 1-2, p. 139-148, 2006.

HABERT, A. C.; BORGES, C. P.; NOBREGA, R. Processos de separação por membranas. Rio de Janeiro: Ed. e-papers, 2006. 180 p.

HOSSAIN, M. M. Concentration of anthocyanin pigments in blackcurrant pomace by ultrafiltration. Food Australia, v. 55, n. 6, p. 263-266, 2003.

KONISHI, S. et al. Análise da influência de agentes solubilizantes na atividade antimicrobiana de extratos de própolis e de uma formulação de spray hidroalcoólico. Mensagem Doce, n. 75, p. 22-25, 2004.

KRELL, R. Value-added products from beekeeping. Rome: FAO, 1996. (FAO Agricultural Services Bulletin, 124) Disponível em: <http://www.fao.org/docrep/w0076e/w0076e00.HTM>. Acesso em: 29 jan. 2008.

KUMAZAWA, S.; HAMASAK, T.; NAKAYAMA, T. Antioxidant activity of various geographic origins. Food Chemistry, v. 84, p. 329-339, 2004.

MAROULIS, Z. B.; SARAVACOS, G. D. Food process design. New York: Marcel Dekker, 2003. (cap. 10). 
MATTA, V. M.; MORETTI, R. H.; CABRAL, L. M. C. Microfiltration and reverse osmosis for clarification and concentration of acerola juice. Journal of Food Engineering, v. 61, n. 3, p. 477-482, 2004.

MELLO, B. C. B. S. Concentração de extratos de própolis através de membranas poliméricas. Campinas, 2008. 110 p. Dissertação (Mestrado) - Universidade Estadual de Campinas - UNICAMP.

MIRANDA, K. F. Estudo da concentração de licopeno por ultrafiltração a partir de suco de melancia (Citrullus vulgaris Schard). Campinas, 2005. 149 p. Dissertação (Mestrado) Universidade Estadual de Campinas - UNICAMP.

MOURA, F. F. Contribuição das propriedades físico-químias e biológicas da própolis produzida por Apis mellifera na Região Nordeste do Brasil. Campinas, 2000.69 p. Dissertação (Mestrado) Universidade Estadual de Campinas - UNICAMP.

PARK, Y. P. et al. Estudo da preparação dos extratos de própolis e suas aplicações. Ciência e Tecnologia de Alimentos, v. 18, n. 3, p. 313-318, 1998.

PETERSON, J.; DWYER, J. Flavonoids: dietary occurrence and biochemical activity. Nutrition Research, v. 18, n. 12, p. 1995-2018, 1998.
PETRUS, J. C. C. Preparação, modificação e caracterização de membranas assimétricas para clarificação de suco de frutas. Campinas, 1997. 139 p. Tese (Doutorado) - Universidade Estadual de Campinas - UNICAMP.

PILIPOVIK, M. V.; RIVEROL, C. Assessing dealcoholization systems based on reverse osmosis. Journal of Food Engineering, v. 69, n. 4, p. 437-441, 2005.

TSUI, E. M.; CHERYAN, M. Membrane processing of xanthophylls in ethanol extracts of corn. Journal of Food Engineering, v. 83, n. 4, p. 590-595, 2007.

USHIKUBO, F. Y.; WATANABE, A. P.; VIOTTO, L. A. Effects of operating conditions and enzyme treatment on fouling and polarized layer formation during umbu (Spondias tuberosa Arr. Cam.) juice microfiltration. Desalination, v. 200, n. 1-3, p. 546-548, 2006.

VINCZE, I.; STEFANOVITS-BÁNYAIB, E.; VATAI, G. Using nanofiltration and reverse osmosis for the concentration of seabuckthorn (Hippophae rhamnoides L.) juice. Desalination, v. 200, n. 1-3, p. 528-530, 2006. 